\title{
Exploring residential urban form patterns: a Spanish case study
}

Rapid urban growth in recent years has increasingly compromised urban environments and made urban sustainability assessment quite challenging. Breaking down the city structure into smaller systems enables its complexity to be simplified. This work provides a methodology for defining the urban taxonomy of cities by characterising the urban form patterns of its residential building stock into four different scales. The methodology enables the urban morphology of the city to be standardised, overcoming the barrier of building stock heterogeneity posed by cities, and considers a comprehensive review of the historic and urban planning development as starting point. The methodology proposed herein is supported by GIS technology and can be applied to medium-sized cities. It was validated by applying to the city of Castellón de la Plana, a Spanish Mediterranean coastal city. As main outcome of this research, the urban taxonomy has been obtained and building types in an average block have been standardised, allowing the definition of representative urban form patterns. This methodology can be useful for the stakeholders involved in urban decision-making processes when analysing socioeconomic aspects, energy issues, the impact of different technological options or the promotion of sustainable urban development initiatives, among others.

Keywords: urban sustainability; urban taxonomy; residential building stock; building typology; construction techniques; GIS

\section{Introduction}

Urban population growth and the rural exodus to cities have led cities to rapidly expand in recent years. Generally, this has caused the disorganised growth of the urban planning of cities, where efforts focused mainly on land use optimisation as an economic asset instead of taking into account the conservation of these environmental and cultural issues (Rueda, Cuchí, Subirats, de Mingo, \& Díaz, 2007). Consequently, urban environments and urban sustainability have become increasingly compromised. More specifically, in 
recent years there has been a prolific scientific interest in medium-sized cities in territorial planning issues, as they offer great potential to promote rural and regional development, reduce poverty and mitigate migration to large cities (Pasciaroni, 2012).

With the emergence of the term Sustainable Development (Brundtland, 1987), the research community has made many efforts to develop tools to assess the urban sustainability of cities by means of indicators. BREEAM Communities (BRE Global, 2016), LEED ND (US GBC, 2009), CASBEE UD (IBEC, 2007) or ECOCITY (Gaffron, Huismans, \& Skala, 2005) are some examples of reference urban sustainability assessment tools in the international context.

Braulio-Gonzalo, Bovea and Ruá (2015) proposed a structure for classifying urban sustainability indicators based on 14 categories after conducting a comprehensive review of the 786 indicators contained in 13 selected tools. On the one hand, the study highlighted that the design of a city shapes many physical, environmental and socioeconomic aspects and, on the other hand, they concluded that the urban morphology of a city is the most strongly related aspect to other categories, such as site and soil, building and housing, energy, mobility and transport. This is why it requires special attention when assessing urban sustainability.

Thus, the intrinsic complexity and heterogeneity of cities implies difficulties when evaluating different aspects, so breaking down the city structure into smaller systems enables this complexity to be simplified and analysed. These smaller urban systems result in urban form patterns of the residential building stock. Several studies have addressed the residential stock classification for different purposes. Theodoridou, Papadopoulos and Hegger (2011b) did a statistical analysis of the Greek residential building stock and provided detailed information to highlight the problems associated with delays in meeting the requirements established by the Directive on the Energy Performance of Buildings 
(EPBD, 2010). In another step, they analysed building typologies according to year of construction, and also to technical, historical, political and social proceedings, in order to promote energy renovation scenarios (Theodoridou, Papadopoulos, \& Hegger, 2011a).

Dall'O', Galante and Torri (2012) proposed an energy performance classification methodology of the residential building stock applied to a city in the Lombardi region (Italy), which was supported by a Geographical Information System (GIS). The described methodology was based on available information, such as cartographic documentation, thematic maps and on-site surveys. Also in Italy, Ascione et al. (2013) characterised the energy performance of new and existing buildings by combining an analytical methodology with GIS, which enabled the results to be plotted on urban energy maps and also to position the buildings with higher energy needs to be identified.

With a more holistic approach, the TABULA Project (Loga et al., 2012) established a common European framework for classifying building typologies that include typical building construction data, performance of supply systems, frequencies of building and systems types and advanced energy conservation measures. Dascalaki, Droutsa, Balaras, and Kontoyiannidis (2011) used this approach to assess the energy performance of residential buildings in Greece. Also Florio and Teissier (2015) considered TABULA to estimate the energy performance certificate of the housing stock characterised via qualitative variables in France, in order to develop a fuel poverty evaluation tool.

As seen above, most of the proposed methodologies focused on classifying the building stock from an energy viewpoint, which reflects the direct relationship of buildings with energy-related aspects. Cheng and Steemers (2011) also developed a model to predict the energy consumption and carbon dioxide emissions of the existing English housing stock by adopting an occupancy pattern that derived from household 
employment status data, and then integrated the socio-economic factor. This occupancy pattern was related to a buildings classification according to type and age. Futcher \& Mills (2013) examined the association between energy building operational and the role of urban form, demonstrating that as we move towards a low energy future, the role of urban form becomes increasing significant.

Note that these studies addressed the built environment from a building perspective, but did not integrate the urban scale and its interaction with the building. In contrast, Ghosh and Vale (2009) presented an urban taxonomy or classification system for New Zealand settlement forms across five urban scales, from the metropolitan to the building scales. By considering a set of basic quantitative urban form descriptors, such as built-up roof areas, productive land, household densities or vegetation, their work concluded that these can be linked to the appraisal of environmental sustainability performances of different urban forms. Going a step further but incorporating the automation of data collection and map characterisation based on digital maps, there is an emerging literature. Biljecki et al. (2014) discussed 3D city modelling, providing a formal and consistent framework to define discrete and continuous six levels of detail with their metrics, quantification and relations among them. Barnsley and Barr (1997) presented a preliminary test of a graph-based, structural pattern recognition system used to infer broad categories of urban land-use from very fine spatial resolution, remotely-sensed images, allowing the structural properties of, and relations between, discrete land-cover parcels to be analysed and interpreted. More recent approaches tested different methods to extract information about the built environment from digital maps and use that information to infer building age (Alexander, Lannon, \& Linovski, 2009). These methods included different types of shape recognition of plan form and of identification of contextual geography; for instance, distance from entrance to the nearest road. Finally and also in 
this line, Mesev (2003) outlined a building disaggregated model that infer urban land use distributions that can be used to inform classified imagery of urban areas, by means of integrating GIS data with remote sensing. The model is based on knowing digital postal records of every delivery address in a city, both residential and commercial properties, which introduces a number of key indicators of density (compactness versus sparseness) and arrangement (linearity versus randomness).

Despite the existing literature in this field, no study to date adopts a classification of urban form patterns considering the scales that compound the city, relating the building with the urban context, and which adapts to the context-specific features of European countries. This work bridges this gap and provides a methodology to characterise urban form patterns and to then define the urban taxonomy. The aims of the study are the proposal of a method for standardising urban morphologies, which overcomes the building stock heterogeneity barrier posed by cities, and also the identification of smaller urban systems to facilitate some specific urban sustainability aspect to be assessed. The outcomes of this research allow representative urban form patterns to be identified, by means of GIS technology. The methodology proposed herein was validated by applying to the city of Castellón de la Plana (east Spain), as case study.

\section{Methodology to characterise urban form patterns}

This work presents a methodology to characterise the urban taxonomy of a city in order to identify the typical urban form patterns of residential building stocks. The proposed methodology consists of six stages that disaggregate the city from larger to smaller urban units, which are: Stage 1) city background by exploring the urban development and the evolution of building construction techniques over time, Stage 2) city scale, Stage 3) neighbourhood scale, Stage 4) urban block scale, Stage 5) building scale, Stage 6) association between residential blocks and building types. Stage 6 results in a set of 
characteristic urban patterns of the city that enable urban morphologies to be standardised. Thus, the purpose of the methodology is to break down the city into four main scales, being the city, the neighbourhood, the urban block and the building.

This method can be applied to medium-sized cities, which are characterised both by their urban and socio-economic structure. Considering urban quantitative criteria, European medium-sized cities are characterised by a population of 20,000 up to 200,000 and medium densities (Rivkin \& Rivkin, 1982) and are generally geographically embedded within larger metropolitan regions, on the edge of or in between metropolitan regions or in the geographical periphery of Europe, according to Kunzmann (2009). Regarding qualitative criteria, medium-sized cities usually have a mix of supply, development and relief functions, offering a wide range of job opportunities, and then bringing the ability to receive and retain migrants from smaller cities or rural areas (Pasciaroni, 2012).

The scheme of the methodology is shown in Figure 1 as a flow chart and each stage is described below. Using GIS enables the application of the methodology automating the data collection process and conducting the disaggregation of urban information into the four urban scales, from larger to smaller. GIS combine cartography and geo-referenced information that enable digital urban maps to be viewed. Then, GIS provides a useful database that contains the information provided by the General Cadastre Office of Spain (DGC, 2014), such as cadastral reference, year of construction, type of building, building height (number of floors), land surface and built area, is created, which allows building types to be identified in a specific urban area. The methodology is subsequently applied and validated through a city, as case study.

Figure 1. Methodology to characterise urban form patterns 
- Stage 1: city background. The urban development of the city and the evolution of building construction techniques across time periods are comprehensively analysed to understand the historic facts that have led to the current state and city morphology.

- Stage 2: city scale. The urban layout is identified in this stage. Urban development is greatly influenced by the physical conditions (climate, orography, etc.), and socio-economic and historical features of each urban area. Although many classifications of urban layouts exist (Marshall, 2005), only four are normally identified in a compact European city:

- Irregular: consists in a network of disorganised arterials with no specific pattern.

- Radial: a special kind of tree structure with a familiar "hub-and-spoke" arrangement.

- Linear: a spinal structure with no branches.

- Grid: organises the streets that meet at right angles to each other to form an orthogonal grid.

Some examples of cities, according to this classification, are shown in Figure 2. The identification of these urban patterns can be done by observing the urban morphology of the city by means of GIS cartography and historic city urban maps.

Figure 2. Examples of typical urban layouts

- Stage 3: neighbourhood scale. In the city, neighbourhoods are smaller urban systems. Four types of neighbourhoods are usually distinguished for historical reasons in European countries, and also due to the evolution of the urban fabric (Prieto Medina et al., 2017). They are outlined below according to their morphology: 
- Historical centre formed by the traditional city centre, together with enlargements included in the walls of the Middle Age city. This type is characterised by an irregular layout, so blocks display no definite layout and anarchic structures are frequent. Streets tend to be narrow and of variable widths. Buildings of different heights stand together, which obstructs appropriate solar insolation. Typical buildings in historical centres are single-family (SF) houses and multi-family (MF) houses with internal light wells.

- Expansion districts near the city centre formed by the first urban peripheral housing development close to the historical centre. In expansion districts, the urban layout has been conducted by an urban plan, so a more organised urban structure results where a regular grid can be found. Here the building type is predominantly the MF house kind, sometimes, together with older SF houses. Streets are wide and buildings have a medium-high rise, which leads to high urban density.

- New development districts where modern neighbourhoods are intended for both working and medium-high social classes. It consists of new residential neighbourhoods with low or medium density. MF-type buildings are frequent and form gated condominiums, together with SF houses that are detached, semidetached or terraced.

- Suburban districts or outlying housing, which arise on the outskirts and usually form small urban areas with a low-income population.

Different kinds of neighbourhoods at his stage are identified by analysing the city structure and recognising similar urban patterns of groups of buildings, which are in turn, strongly influenced by the urban sprawl across historic time periods. 
- Stage 4: residential block scale. On the residential block scale, each block is considered a unit formed by a group of buildings. It has a particular shape depending on urban variables, such as street geometry (building height and street width), existence of inner building light wells and inner block courtyards, presence of detached or terraced buildings, and urban density. They are all factors that determine the structure of the block pattern. GIS software enables conducting this stage by getting information from the urban database and distinguishing between different building typologies grouped into residential blocks.

- Stage 5: building scale. Building types define the urban landscape in the city. Two factors are considered to characterise residential building types:

- building class and

- year of construction period.

Regarding building class, three criteria were taken into account to do the classification: if the building is SF or MF, number of floors, and if terraced or detached. These factors determine building size. Year of construction can be defined according to the historical evolution of the city. This cadastral information for each existing building within the urban area is contained in the GIS database, as seen in Figure 3. By crossing both factors, that is building class and year of construction, we can obtain a matrix of building typologies for a specific area or for the entire city.

Figure 3. Cadastral information data management in GIS

- Stage 6: association of block pattern and building type. Once the block patterns and building types have been identified, they can be associated to identify representative urban patterns in a given urban area, by using GIS software. As a 
result, the characteristic urban taxonomy in a specific area is found to be representative of the entire urban area or specific neighbourhoods or districts.

\section{Applying the methodology to the city}

The proposed methodology was applied to the city Castellón de la Plana, stage by stage and as described in the previous section. The result of the implementation is to identify the urban form patterns in the city, which link urban layout with blocks and building types. Besides, an urban GIS database of the city that allows urban information to be processed and urban maps to be generated is created.

Castellón de la Plana (east Spain) is a medium-sized Mediterranean coastal city with 180,690 inhabitants (INE, 2018) located at a $39^{\circ} 59^{\prime} 11^{\prime \prime}$ north latitude and a $0^{\circ} 2^{\prime}$ 12" east latitude (see Figure 4). This section firstly describes the urban development of the city since its founding, and secondly the construction techniques used for constructing buildings over time.

Figure 4. Location of Castellón de la Plana

\section{Stage 1: City's background}

\section{- Urban development analysis across time periods}

Castellón de la Plana was conceived as a city in the 13th century, when it was structured into small groups of detached and spread Muslim farmsteads that formed the then Middle Age village. Table 1 summarises the city's evolution according to chronology, and shows the graphical sprawl and the main milestones.

The first settlements were built on the west side of the main irrigation canal, which defined a north-south line. The land towards the east (closer to the seaside) was not 
expanded for years in order to preserve this fertile and suitable land for cultivation. The city was later surrounded by a defensive wall, which can be identified from the current historic city centre. The wall remained until the beginning of the 19th century, when the suburbs that were close to the historical city centre were included due to demographic and economic growth. Demolition of the wall led to new available land, which meant new plots of a 4-metre façade and a depth of $20 \mathrm{~m}$, where it was possible to build up to a height of $6 \mathrm{~m}$. This led to new buildings that rose close to the historical areas, which remain today and are characteristic of the current city centre (Esteve-Comes, 2012).

In 1837 , the city built a new rhomboid-shaped defensive wall. It included the suburbs and many gaps, which were to become the new future neighbourhoods. In 1885 , the first urban plan for the peripheral areas of the city was devised. Walls were completely demolished at the end of the 19th century.

At the beginning of the 20th century, ten neighbourhoods formed the city. The first expansion plan was written in 1911 and the first General Urban Organisation Plan (PGOU in Spanish) was drawn up in 1925. Three urban areas were designed: inner area, first expansion area and new expansion area. However, this plan failed when the Spanish Civil War began. A new plan was approved when this war ended in 1939, which included the new squares and avenues that shaped the city. The Garden City movement (Buder, 1990), which has evolved in Castellón de la Plana to date, has been recently implemented into the new residential neighbourhoods with low-density single-family (SF) houses.

In 1963, a new Castellón PGOU was approved according to the National Land Law of 1956. However, it was not effective. Given the growing demand of new dwellings, the compact growth and integrated green areas concept was lost, even though the main economic activity and traditions in the area were based on agriculture. Rapid demographic growth led to a disproportionate increase in height of buildings and, therefore, to 
increased building density. Disparate heights arose, with 3- or 4-storey buildings standing next to newly built constructions with over eight floors, and even up to 14 . This urban landscape is characteristic of what is now the historical city centre, as seen in Figure 5.

Figure 5. Urban landscape in Castellón de la Plana's city centre

The urban layout in the 1980s and 1990s underwent major transformations. The PGOU further structured the already structured territory. New big urban plans for residential use, and single-family (SF) or multi-family (MF) houses, were implemented into the surrounding areas of the city, where a more regular urban pattern can be found. Currently, the PGOU of the city is being revised and a new version will enter into force shortly. Urban plans of the city are exhaustively listed in Table 2 and the main features are described.

Table 1. Urban sprawl description of Castellón de la Plana

Table 2. Overview of the Castellón de la Plana urban plans

\section{- Evolution of building construction techniques}

Construction techniques in Spain have notably evolved since the end of the second industrial revolution in the late 19th century. Historic facts and milestones, and the introduction of building regulations, determined the change in construction systems and materials, which characterise the structure and envelope of buildings. Table 3 presents the chronological evolution of building elements, including structure, façades, roofs, horizontal and vertical internal partitions and windows, and their relationship with historic facts and regulations. 
In 1939 the Spanish Civil War ended, after which the Reconstruction National Plan and the promotion of reinforced concrete gave way to lighter structures and to double-layer walls. In 1960 the first building technical regulations came into force (Ministerio de la Vivienda, 1957), which established basic guidelines in the construction sector. The 1980s witnessed a major change in construction conditions as the first thermal regulation that introduced thermal-acoustic insulation into the building envelope came into force (NBE-CT-79, 1979). From this point onwards, quality in construction techniques considerably improved. In 2006, the Technical Building Code (CTE, 2006) tightened building requirements, which made the performance of buildings improve. This means that five main time periods can be identified: before 1940, 1940-1959, 1960-1979, 1980-2006 and after 2006.

Table 3. Chronological evolution of construction techniques in Spanish residential buildings 


\section{Stage 2: City scale.}

Firstly, the urban layout of the city was examined by taking into account historical evolution and urban planning considerations as the outlined methodology. Then the cartography from the Cadastre Office and the Urban Plan currently in force were examined to find the typical layout patterns in the city under study. As Figure 6 shows, Castellón de la Plana presents diverse urban layouts depending on the area considered. The historical city centre has an irregular pattern, the traditional and new expansion areas present an orthogonal-grid pattern, and two neighbourhoods present a radial layout.

Figure 6. Urban layout identification in Castellón de la Plana

\section{Stage 3: Neighbourhood scale.}

This Medieval town city responds to the current historical city centre, while expansion districts appeared during the urban evolution from the 17th century surrounding the city centre. Figure 7 graphically shows the urban evolution of the city. As seen, the evolution of built areas is linked to the year of construction of buildings. Dotted lines represent the different present-day neighbourhoods in the city.

Figure 7. Identifying neighbourhoods according to the historical evolution of the city

\section{Stage 4: Urban block scale.}

According to the fourth methodology stage, a more in-depth analysis of the configuration of streets was done to reveal the urban blocks that characterise the urban fabric of neighbourhoods. A GIS database for the city is created at this stage of the methodology implementation. Publicly available Cadastral data were inputted into an open GIS 
software, gvSIG (Asociación gvSIG, 2014). Cadastral data processing was not easy, but tedious and time-consuming. Since the file provided by the Cadastral Office lacked part of the information needed to be used by a GIS database format, and some of the information contained mistakes, that file had to be previously corrected to be used in this study. The file contained 19,315 cadastral references (inputs provided in MS Excel rows) with several pieces of information such as: use of the building (residential, commercial, year of construction, building typology (SF, MF) and number of floors. However, only year of construction could be used directly because the gvSIG software could not interpret the codes that represented building typology and number of floors. Therefore, some tasks were undertaken to convert the information into an appropriate format. Firstly regarding the use of the building, all the data had to be exhaustively checked because the use of the building assigned to each cadastral reference quite often corresponded to the use of the ground floor, but not to the general building use. As a result, many residential mixed-use buildings with commercial ground floors, but with residential use on upper floors, were misidentified as commercial use buildings. Secondly, some simple codes were proposed that fitted the parameters stated in our methodology, and gvSIG could use them.

GIS software allows here to identify street geometry (height and width), the existence of block courtyards or building light well and if buildings are detached or terraced within the urban block. Detached buildings refer to those single free standing buildings, in the form of SF houses or independent MF apartment blocks, while terraced buildings refer to as row buildings forming a residential urban block. Table 4 shows the seven block patterns identified in Castellón de la Plana, their location in the city and building type, together with a brief description. Also the advantages and disadvantages that each urban block implies were discussed, based on urban sustainability criteria regarding urban 
compactness, mixed uses, passive energy performance of buildings and green areas contributing to improve urban microclimate.

Table 4. Urban block typologies in the city and characteristics

\section{Stage 5: Building scale.}

The classification of building types in the entire city was carried out by following Stage 5 presented in the methodology and using GIS software. Regarding building type, the code had to be simplified and the six building typologies identified herein were associated with six different numerical codes (A-F). Number of floors, which was not provided with textual and numerical information by the Cadastre Office, had to be changed by a numeric code, being processed with formulae in the attribute table. Six building classes were obtained (from class A to F) considering if the building is detached or terraced, if it is an SF or an MF building, and number of floors over the ground level, among other characteristics. Table 5 shows the six identified building types in the city and their characteristics.

Table 5. Identification of building classes in the city

Figure 8 shows the distribution of buildings per building class in the city Castellón de la Plana in a GIS environment.

Figure 8. The GIS view of the building classes in the city

As for year of construction, historical events greatly influence housing needs. For instance in Spain, the Civil War (1936-1939) led to an acute housing need after 1939. These buildings were characterised by poor quality materials and short-term construction 
because the primary need of housing quantity prevailed over quality standards. Besides historical events, construction systems change as technologies evolve. Therefore, year of construction implies different structural systems, façade layers, roofs and fenestrations. Regulations on the construction sector, especially those related to thermal condition requirements, are implicit on year of construction, so it provides valuable information about construction building techniques. According to Table 3, five main temporal periods were identified: before 1940, 1940-1959, 1960-1979, 1980-2006 and after 2006. Figure 9 presents the distribution of buildings per year of construction in the city Castellón de la Plana in a GIS environment. When crossing the building class with the year of construction, we obtain a matrix that classifies the building typology. This breaks down the possible 30 types and indicates the number of buildings included in each one, as presented in Figure 10. As Figure 10 illustrates, a great increase in the construction of residential buildings after the Spanish Civil War is identified, which implies the existence of a large residential stock under the current building regulations requirements.

Figure 9. The GIS view of building year of construction in the city

Figure 10. Matrix of the number of buildings typologies (cumulative) for the entire city and residential buildings construction evolution in Castellón de la Plana

\section{Stage 6: Association of block pattern and building type.}

Having described the four urban scales in previous stages, the urban taxonomy can be drawn, as shown in Figure 11. This links building types with residential blocks, where they can be located and, in turn, the residential blocks are also linked with the kinds of neighbourhoods that can contain them.

Figure 11. The city's urban taxonomy 
As noted in Figure 11, building typology and urban morphology are strongly related in some cases. For instance, building types A and B can be placed only in Block 5 because of the intrinsic morphology of this kind of buildings and the residential block. The same occurs with E, which can be found only in Block 6, located in new urban developments and suburban districts. Building types C, D and F can be found in Blocks 1, 2 and 3, mostly located in the historical centre and the nearby expansion districts. D can be also found in Block 4 and F in Block 7, and the latter corresponds to the medium or high class terraced houses located in new development districts.

By way of example, Figure 12 shows the results in a neighbourhood of the city, Parque del Oeste, where the implementation of the methodology resulted in the configuration of the standard residential urban blocks pattern (Block 2 and Block 3). By gvSIG, the percentages of building types included in each block pattern were obtained, as seen in Table 6 . This presents the number of buildings and the built area, in square metres, per building class and urban block. The implementation of the methodology thus allowed building types in an average block to be standardised.

Figure 12. The GIS view of building classes and block types in the neighbourhood Parque del Oeste

Table 6. Number of buildings, built area $\left(\mathrm{m}^{2}\right)$ and percentage (\%) per building class and urban block in the neighbourhood (Parque del Oeste) 


\section{Discussion and conclusion}

This paper proposed a methodology for characterising the urban form patterns of residential building stocks and its application to the city of Castellón de la Plana. This work described the urban development of the city and the urban planning that shaped its current morphology. The urban fabric responds to city urban sprawl, so that history and architectural identity of the city are decisive to understand the current morphology. Construction evolution of buildings were also explored and five temporal periods classified by year of construction were identified after taking into account building regulations, historical milestones and construction techniques of the region. Each period involved different solutions for structure and envelope elements, which implied similar characteristics for the buildings built in the same period of time. The methodology stated herein can be applied to medium-sized cities with similar characteristics to the city described and is a starting point for further research when investigating different purposes on the matter of urban sustainability.

The decomposition of the city into smaller urban systems helps simplify the complexity and work with urban form patterns that characterise the residential building stock. As a main application, the method allows stakeholders involved in urban processes, such as local authorities, architects, urban planners and engineers, to establish environmental policies and programmes to promote sustainable urban development initiatives. It can help identify vulnerable neighbourhoods, which include the oldest buildings in a bad state of preservation or those that do not meet current regulation requirements, in order to set priority guidelines when building refurbishment processes, and also when urban regeneration projects have to be conducted locally. Besides, the method described can be used where a combination of various urban land uses exist, such 
as commercial, institutional or recreational, since the GIS database of the city enables distinguishing which kind of buildings compose mixed urban blocks.

This method can also be used to identify the most typical block and building class in an urban area, as well as the predominant year of buildings construction, in order to investigate a specific field. In energy efficiency terms, this enables urban patterns to be standardised and these small urban systems to be energy-assessed in order to extrapolate conclusions on the neighbourhood and city scales. In line with this, Braulio-Gonzalo et al. (2016) used it and proposed a bottom-up-based methodology as a further step to predict the energy performance and indoor thermal comfort of residential stocks by modelling urban form patterns and then conducting stock aggregation to approach the city scale. Since the energy performance of buildings has a great deal to do with the intrinsic design aspects of the built environment (e.g. urban morphology and the physical context of the surrounding built environment), the multi-staged urban taxonomy methodology stated herein enabled significant building and urban aspects for the energy performance of buildings to be identified. Thus, urban morphologies were linked to different energy performances, allowing an energy characterisation of different urban patterns. Furthermore, the study provideds a definition of urban energy maps for the entire city through GIS technology, which immediately provides a visual identification of energy assessment results.

The integration of GIS into the proposed methodology helps create an urban georeferenced database that contains valuable information and facilitates the characterisation of the residential building stock. Plotting information on urban maps helped view the residential stock of the city classified per building type and year of construction. This is considered an important point to help stakeholders make informed and transparent decisions since it enables users to analyse critical issues through a friendly visual 
interface, while it also informs citizens about some specific issues of their dwellings. So the methodology is a transparent instrument for both local authorities and citizens.

As a future development, it is proposed to widen and enhance the current GIS database in order to add any other kind of information on the urban or building scale, such as technological or socio-economic aspects. Crossing such information can provide interesting relationships among different aspects, such as social ones, those linked to the local economy, those related to energy behaviour of building users or those that analyse the environmental impact of different technological options. Relating to the case study, it is proposed to extend the application of the methodology to other city areas in order to characterise urban patterns of the whole city. In addition, it would be interesting to apply the methodology to other European medium-sized cities with the aim of comparing their urban layouts and residential block patterns and also identifying similarities among them. 


\section{References}

Alexander, D. K., Lannon, S., \& Linovski, O. (2009). The identification and analysis of regional building stock characteristics using map based data. In Building Simulation 2009, Glasgow, Scotland July 27-30 (pp. 1421-1428).

Ascione, F., De Masi, R. F., de Rossi, F., Fistola, R., Sasso, M., \& Vanoli, G. P. (2013). Analysis and diagnosis of the energy performance of buildings and districts: Methodology, validation and development of Urban Energy Maps. Cities, 35, 270-283. http://doi.org/10.1016/j.cities.2013.04.012

Asociación gvSIG. (2014). gvSIG Desktop. Retrieved from http://www.gvsig.com/

Barnsley, M. J., \& Barr, S. L. (1997). Distinguishing urban land-use categories in fine spatial resolution land-cover data using a graph-based, structural pattern recognition system. Computers, Environment and Urban Systems, 21(3-4), 209-225. http://doi.org/10.1016/S0198-9715(97)10001-1

Biljecki, F., Ledoux, H., Stoter, J., \& Zhao, J. (2014). Formalisation of the level of detail in 3D city modelling. Computers, Environment and Urban Systems, 48, 1-15. http://doi.org/10.1016/j.compenvurbsys.2014.05.004

Braulio-Gonzalo, M., Bovea, M. D., \& Ruá, M. J. (2015). Sustainability on the urban scale: Proposal of a structure of indicators for the Spanish context. Environmental Impact Assessment Review, 53, 16-30. http://doi.org/10.1016/j.eiar.2015.03.002

Braulio-Gonzalo, M., Bovea, M. D., Ruá, M. J., \& Juan, P. (2016). A methodology for predicting the energy performance and indoor thermal comfort of residential stocks on the neighbourhood and city scales. A case study in Spain. Journal of Cleaner Production, 139, 646-665. http://doi.org/10.1016/j.jclepro.2016.08.059

BRE Global. (2016). BREEAM web page. Retrieved 15 May 2015, from http://www.breeam.org/page.jsp?id=346

Brundtland, G. H. (1987). Report of the World Commission on Environment and Development: Our Common Future. Oslo.

Buder, S. (1990). Visionaries and Planners: The Garden City Movement and the Modern Community. New York: Oxford University Press.

Cheng, V., \& Steemers, K. (2011). Modelling domestic energy consumption at district scale: A tool to support national and local energy policies. Environmental Modelling \& Software, 26(10), 1186-1198. http://doi.org/10.1016/j.envsoft.2011.04.005

CTE. Real Decreto 314/2006, de 17 de marzo, por el que se aprueba el Código Técnico de la Edificación, Pub. L. No. Real Decreto 314/2006 (2006). España.

Dall'O', G., Galante, A., \& Torri, M. (2012). A methodology for the energy performance classification of residential building stock on an urban scale. Energy and Buildings, 48, 211219. http://doi.org/10.1016/j.enbuild.2012.01.034

Dascalaki, E. G., Droutsa, K. G., Balaras, C. A., \& Kontoyiannidis, S. (2011). Building typologies as a tool for assessing the energy performance of residential buildings - A case study for the Hellenic building stock. Energy and Buildings, 43(12), 3400-3409. http://doi.org/http://dx.doi.org/10.1016/j.enbuild.2011.09.002 
DGC. (2014). Dirección General del Catastro. Retrieved from http://www.catastro.meh.es/

EPBD. European Directive 2010/31/UE on the energy performance of buildings (2010). Retrieved from http://eur-lex.europa.eu/legal-content/EN/ALL/?uri=CELEX:32010L0031

Esteve-Comes, A. (2012). Paseando por las calles de Castellón. (Creamos talentos literarios, Ed.). Castelló de la Plana.

Florio, P., \& Teissier, O. (2015). Estimation of the Energy Performance Certificate of a housing stock characterised via qualitative variables through a typology-based approach model: A fuel poverty evaluation tool. Energy and Buildings, 89, 39-48. http://doi.org/10.1016/j.enbuild.2014.12.024

Futcher, J. A., \& Mills, G. (2013). The role of urban form as an energy management parameter. Energy Policy, 53, 218-228. http://doi.org/10.1016/j.enpol.2012.10.080

Gaffron, P., Huismans, G., \& Skala, F. (2005). Ecocity book I: a beter place to live. Vienna.

Ghosh, S., \& Vale, R. (2009). Typologies and Basic Descriptors of New Zealand Residential Urban Forms. Journal of Urban Design, 14(4), 507-536. http://doi.org/10.1080/13574800903265371

IBEC. (2007). CASBEE UD Comprehensive Assessment System for Built Environment Efficiency for Urban Development. Technical manual 2007 edition.

INE. (2018). Spanish Statistical Office. Retrieved from http://www.ine.es/

Kunzmann, K. R. (2009). Strategic Planning and Creative Governance in the South Baltic Arc, $1-22$.

Loga, T., Diefenbach, N., Stein, B., Balaras, C. A., Villatoro, O., \& Wittchen, K. B. (2012). Typology Approach for Building Stock Energy Assessment. Main Results of the TABULA project. Darmstadt. Retrieved from http://www.buildingtypology.eu/tabulapublications.html

Marshall, S. (2005). Streets \& patterns. New York: Taylor \& Francis.

Mesev, V. (2003). Neighborhood pattern recognition from mailing information: Links with satellite imagery. Journal of Space Communication, (3).

Ministerio de la Vivienda. Normativa técnica de la edificación del Ministerio de Vivienda (1957). España.

NBE-CT-79. Real Decreto. Norma Básica de la Edificación sobre condiciones térmicas en los edificios, Pub. L. No. BOE 253 (1979). España. Retrieved from http://www.boe.es/buscar/doc.php?id=BOE-A-1979-24866

Pasciaroni, C. (2012). Ciudades medias: Aproximación Metodológica, Funcionalidades y Estructura Productiva. Ciencias Económicas, 30(1), 399-415.

Prieto Medina, P., Romero de Ávila Serrano, V., De, M. E., Salamanca, A., Solís Trapero, E., \& Coronado Tordesillas, J. M. (2017). Identifiación , clasificación y análisis de las formas urbanas en ciudades medias: aplicación a las capitales provinciales de Castilla-La Mancha. Anales de Geografía de La Universidad Complutense, 38(1), 87-112. http://doi.org/http://dx.doi.org/10.5209/AGUC.60470 
Rivkin, G. W., \& Rivkin, L. D. (1982). Approaches to Planning for Secondary Cities in Developing Countries.

Rueda, S., Cuchí, A., Subirats, J., de Mingo, M., \& Díaz, A. (2007). Libro Verde de Medio Ambiente Urbano. Madrid: Ministerio de Medio Ambiente.

Theodoridou, I., Papadopoulos, A. M., \& Hegger, M. (2011a). A typological classification of the Greek residential building stock. Energy and Buildings, 43(10), 2779-2787. http://doi.org/http://dx.doi.org/10.1016/j.enbuild.2011.06.036

Theodoridou, I., Papadopoulos, A. M., \& Hegger, M. (2011b). Statistical analysis of the Greek residential building stock. Energy and Buildings, 43(9), 2422-2428. http://doi.org/10.1016/j.enbuild.2011.05.034

US GBC. (2009). LEED ND Leadership in Energy and Environmental Design for neighborhood development. (The U.S. Green Building Council, Ed.). 
Table 1. Urban sprawl description of Castellón de la Plana

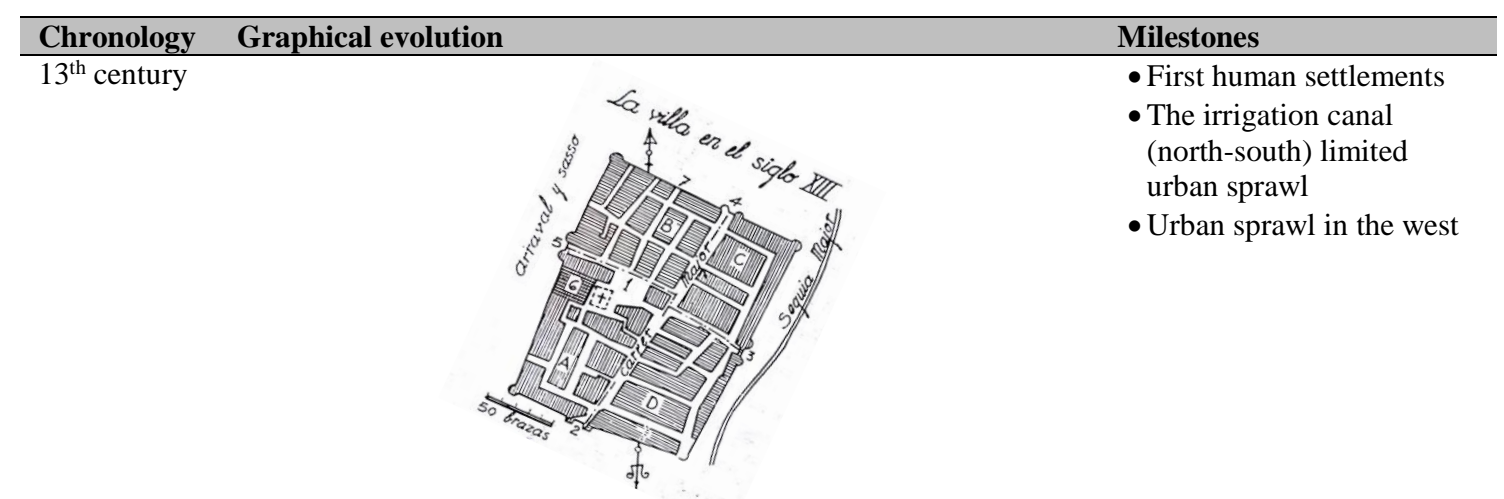

(Sánchez Adell, Olucha Montins, \& Sánchez Almela, 1993)

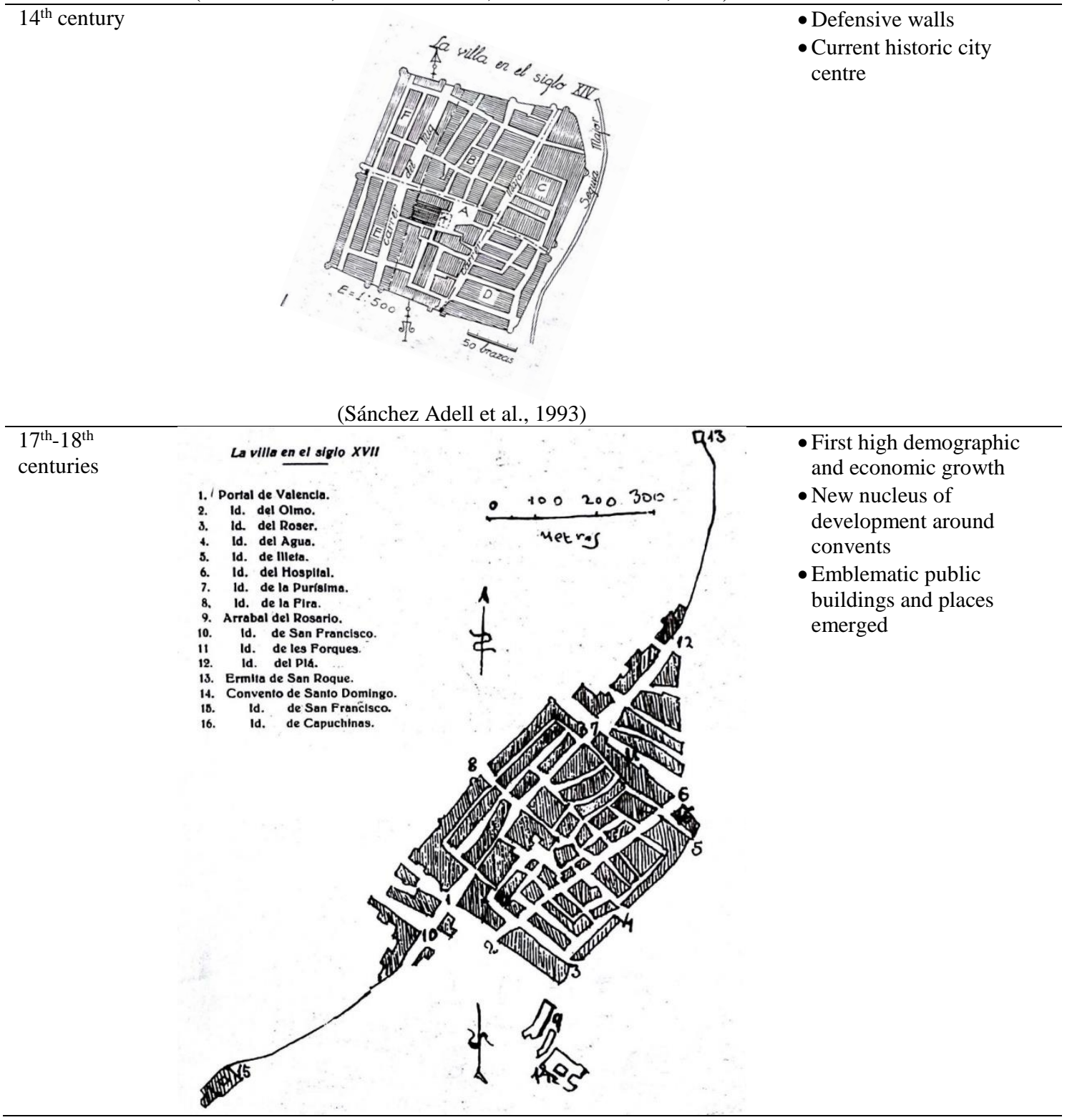




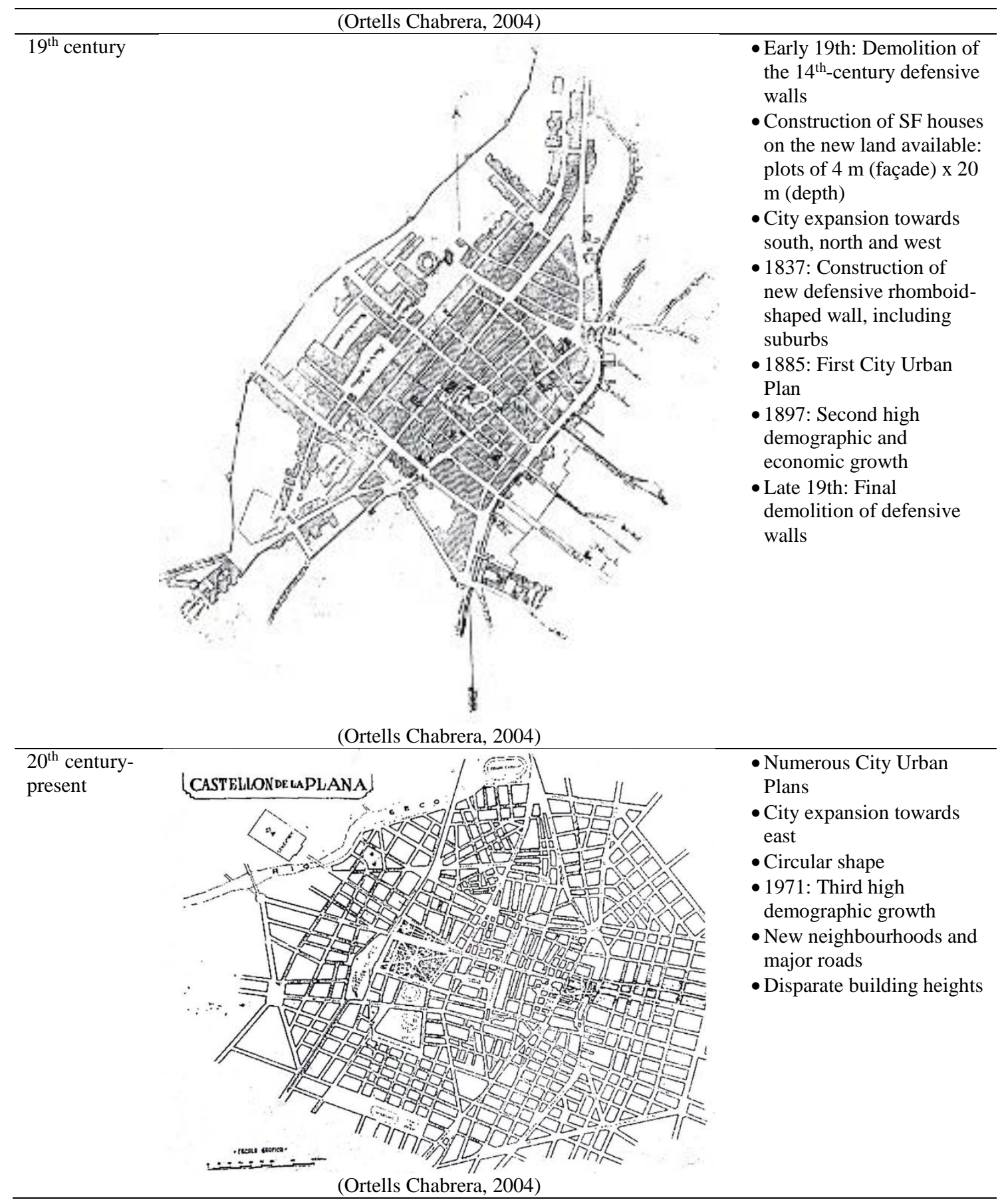


Table 2. Overview of the Castellón de la Plana urban plans

\begin{tabular}{|c|c|c|}
\hline Year & Urban plan & Features \\
\hline 1885 & Plan (Godofredo Ros de Ursinos) & Planning 1 for the peripheral south-east \\
\hline 1890 & South-east plan & Planning 2 for the peripheral south-east \\
\hline 1914 & Expansion plan (Josep Gimeno Almela) & Planning for expansion city areas \\
\hline 1925 & Plan (Vicente Traver Tomás) & $\begin{array}{l}\text { Definition of three areas: city centre, expansion districts } \\
\text { and garden city } \\
\text { Failed }\end{array}$ \\
\hline 1939 & Plan (Vicente Traver Tomás) & $\begin{array}{l}\text { Creation of new major streets and squares } \\
\text { Failed }\end{array}$ \\
\hline 1958 & Ordinances for construction and sewerage & Transition to new urban plans \\
\hline 1963 & $\begin{array}{l}\text { PGOU (Romaní Miquel, Prades Safont, Vicente } \\
\text { Traver Espressati) }\end{array}$ & $\begin{array}{l}\text { Adaptation to the National Land Law of } 1956 \\
\text { Globalising city approach } \\
\text { Failed }\end{array}$ \\
\hline 1984 & PGOU & $\begin{array}{l}\text { Correction of the negative points of the previous Plan: } \\
\text { disparate building heights, lack of services and facilities } \\
\text { areas }\end{array}$ \\
\hline 2000 & PGOU & $\begin{array}{l}\text { New expansion districts: PERI 19, PAU Lledó, PAU } \\
\text { Gumbau, PERI 18, PAU Censal and the Universitat } \\
\text { Jaume I district } \\
\text { Repealed }\end{array}$ \\
\hline present & PGOU under review & - \\
\hline
\end{tabular}


Table 3. Chronological evolution of construction techniques in Spanish residential buildings

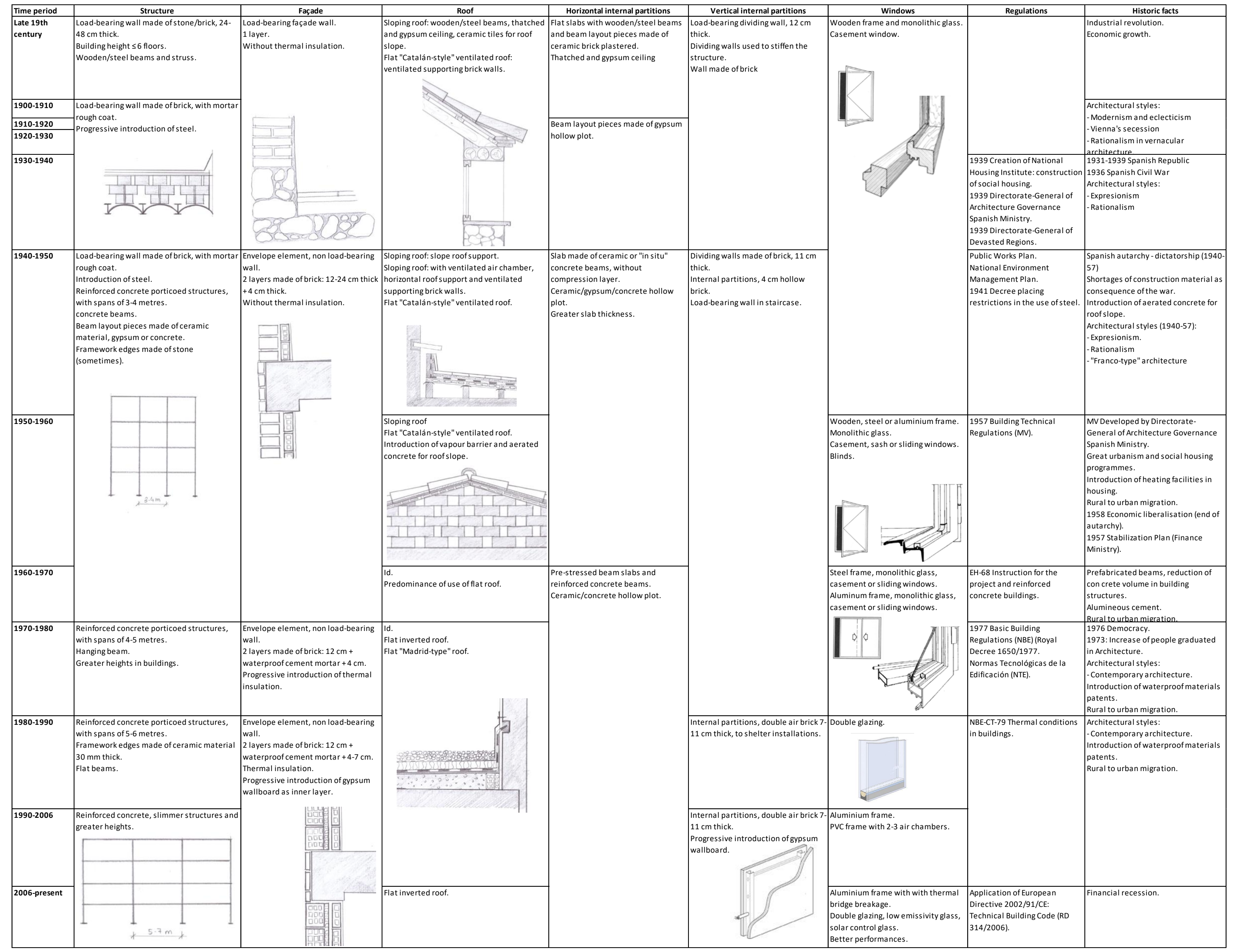




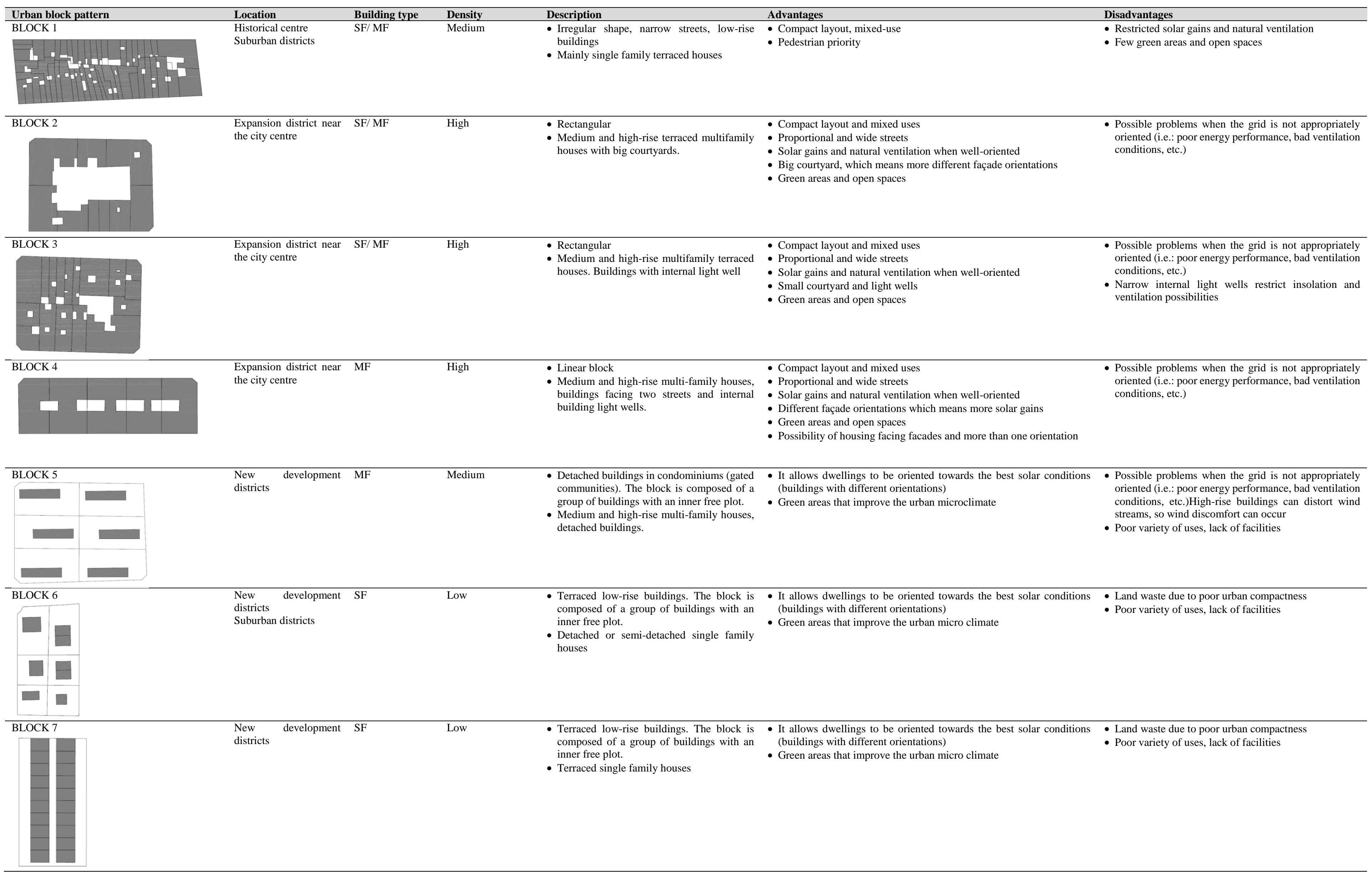


Table 5. Identification of building types in the city

\begin{tabular}{|c|c|c|c|c|}
\hline $\begin{array}{l}\text { Building } \\
\text { class }\end{array}$ & Location & MF/ SF & $\begin{array}{l}\text { Detached/ } \\
\text { Terraced }\end{array}$ & $\begin{array}{l}\text { No. of } \\
\text { floors } \\
\end{array}$ \\
\hline A & New development districts & MF & Detached & $\leq 4$ \\
\hline B & New development districts & MF & Detached & $>4$ \\
\hline $\mathrm{C}$ & $\begin{array}{l}\text { Historical centre } \\
\text { Expansion district near the city centre } \\
\text { Suburban districts }\end{array}$ & MF & Terraced & $\leq 4$ \\
\hline $\mathrm{D}$ & Expansion district near the city centre & MF & Terraced & $>4$ \\
\hline E & New development districts & SF & Detached & $\leq 4$ \\
\hline $\mathrm{F}$ & $\begin{array}{l}\text { New development districts } \\
\text { Suburban districts } \\
\text { Historical centre }\end{array}$ & SF & Terraced & $\leq 4$ \\
\hline
\end{tabular}

Table 6. Number of buildings, built area $\left(\mathrm{m}^{2}\right)$ and percentage $(\%)$ per building class and urban block in the neighbourhood (Parque del Oeste)

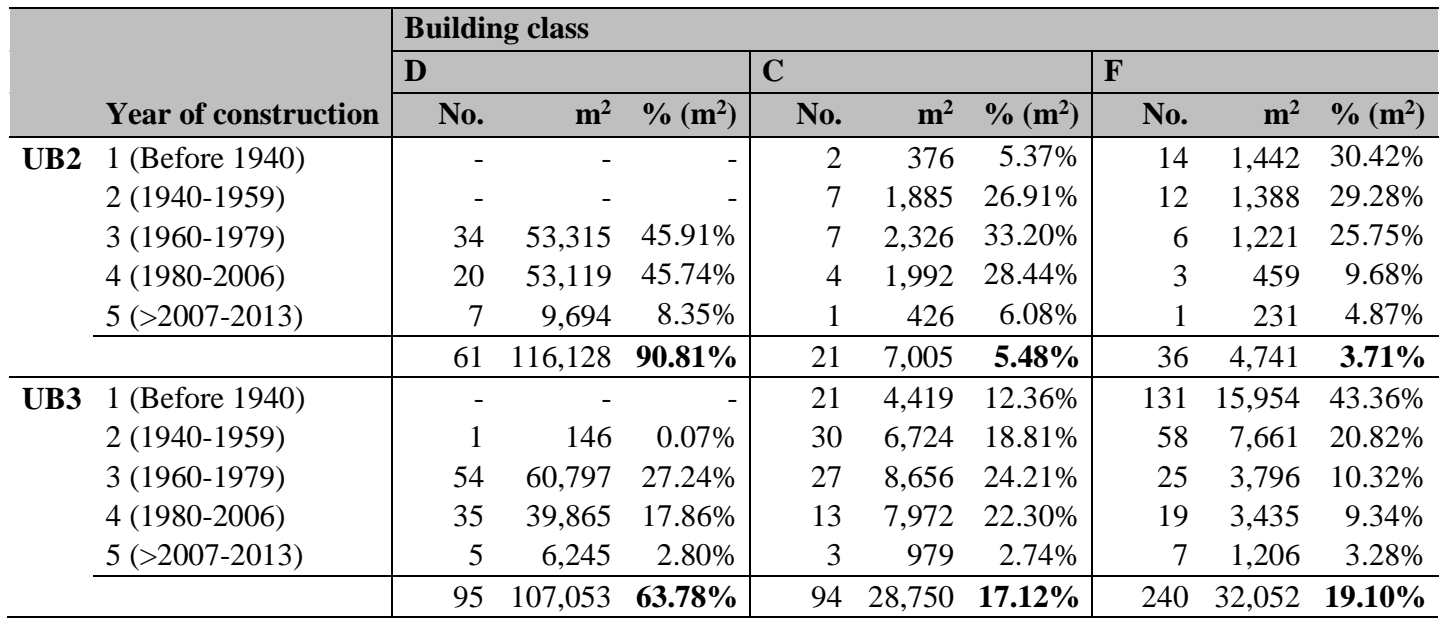




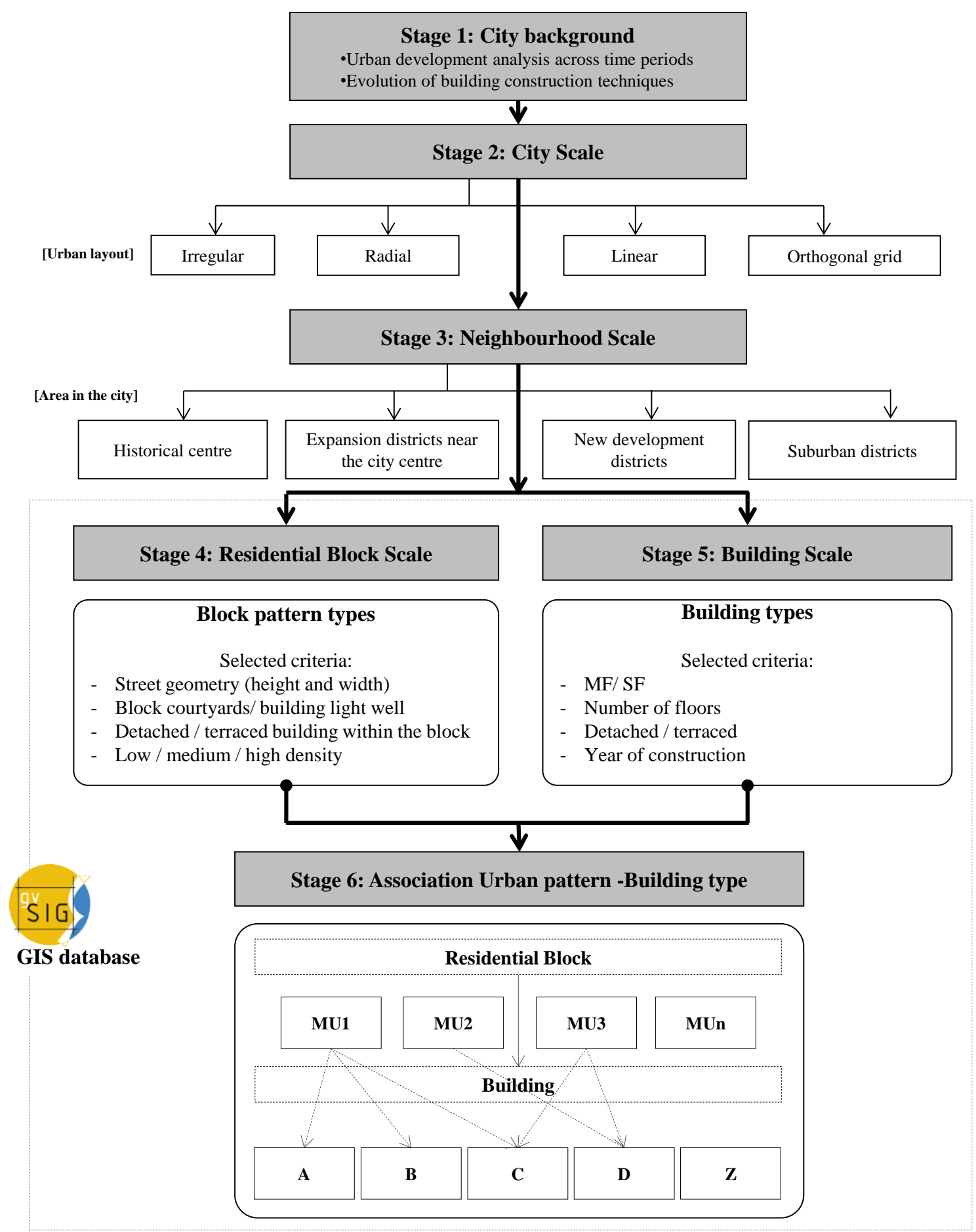

Figure 1. Methodology to characterise urban form patterns 


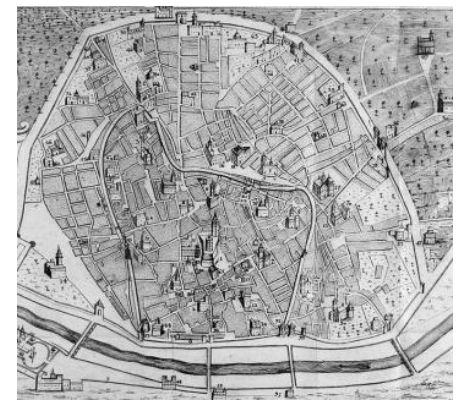

Irregular

Example: Historical centre, Valencia (Spain)

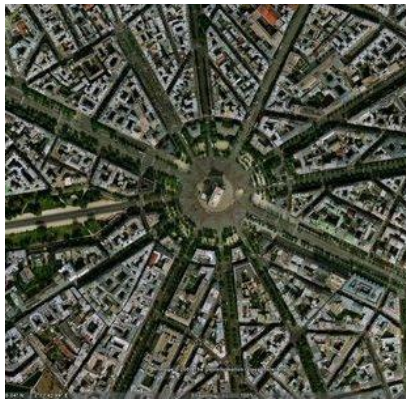

Radial

Example: Paris (France)

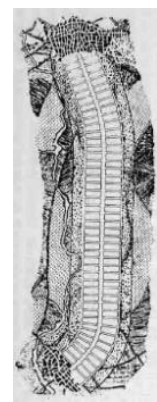

Linear

Example: Linear City, Madrid

(Spain)

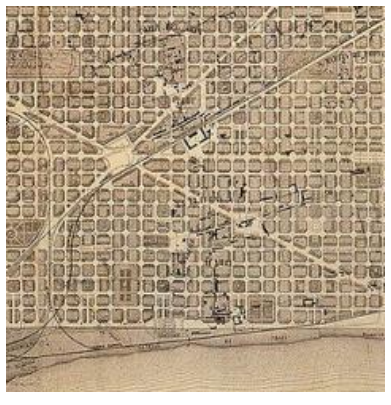

Grid

Example: Expansion District, Barcelona (Spain)

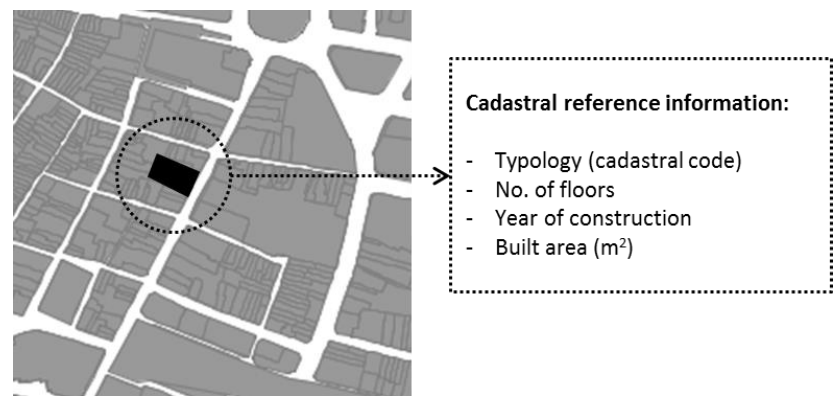



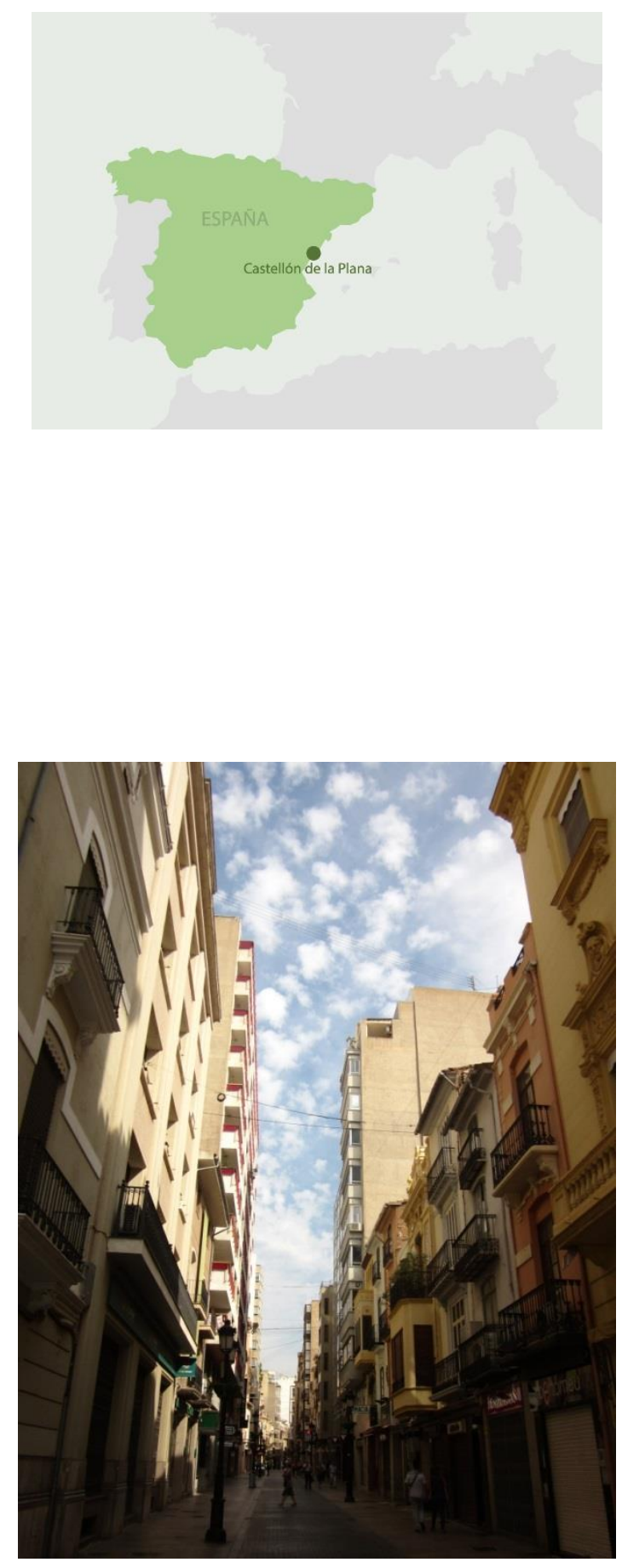

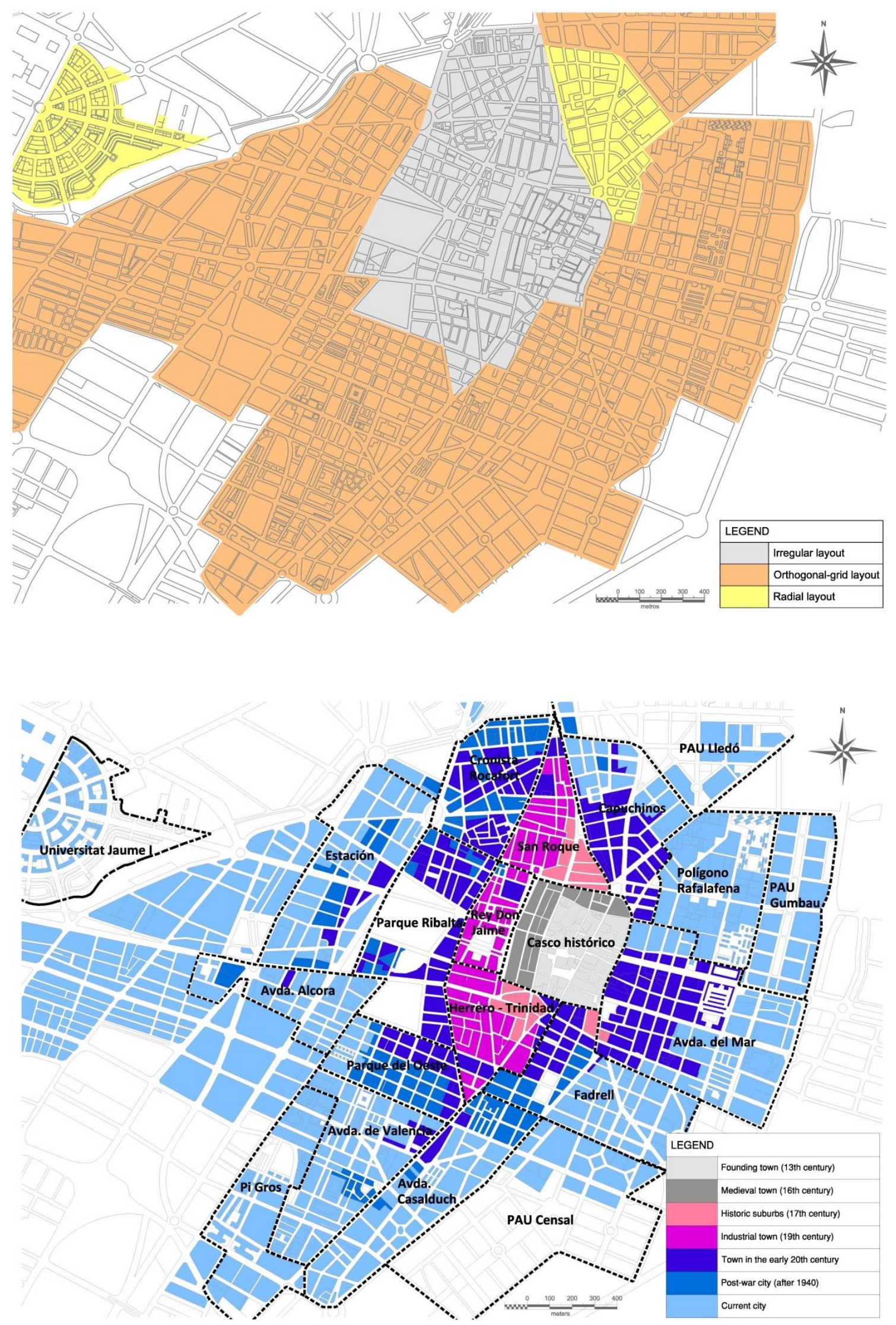


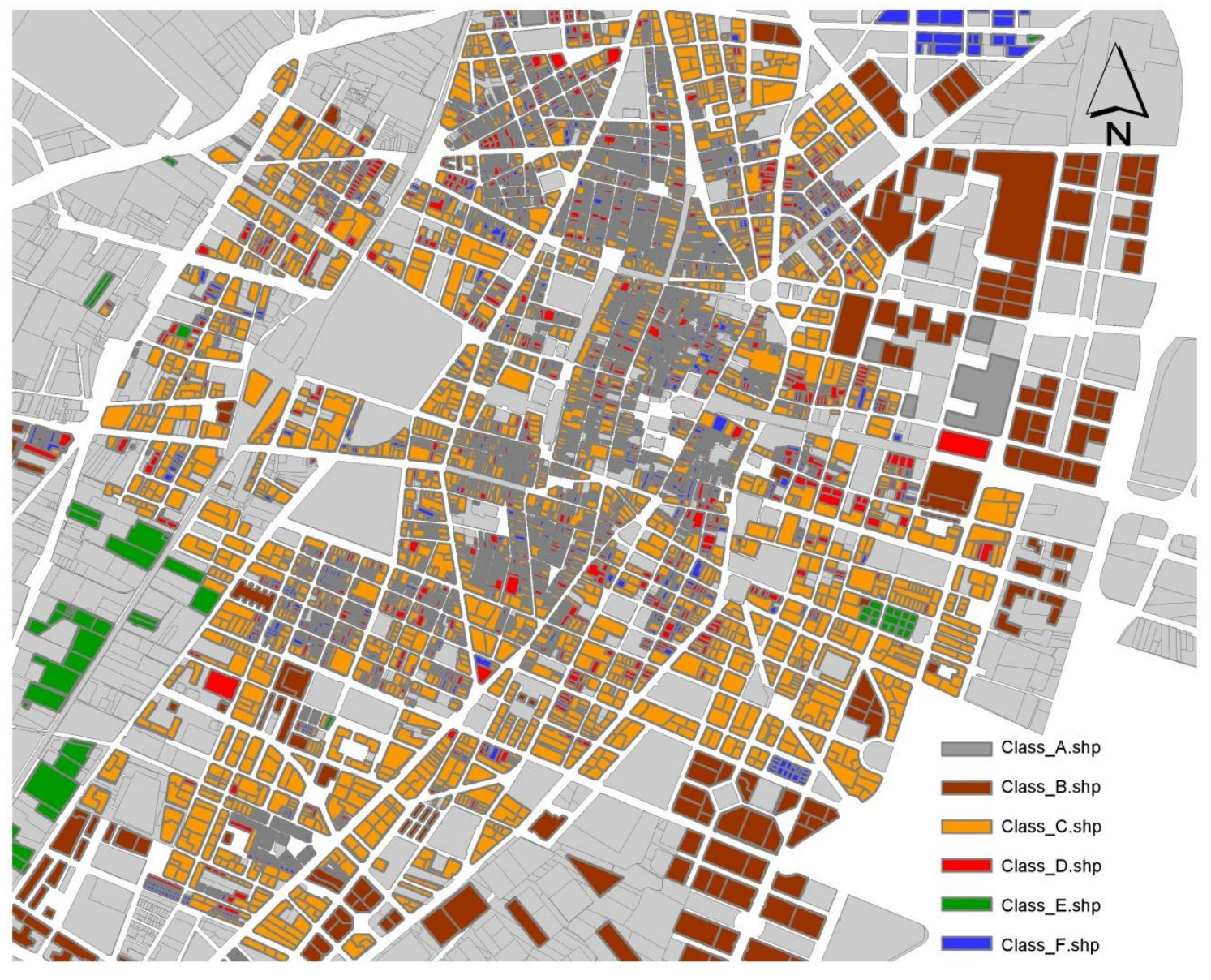



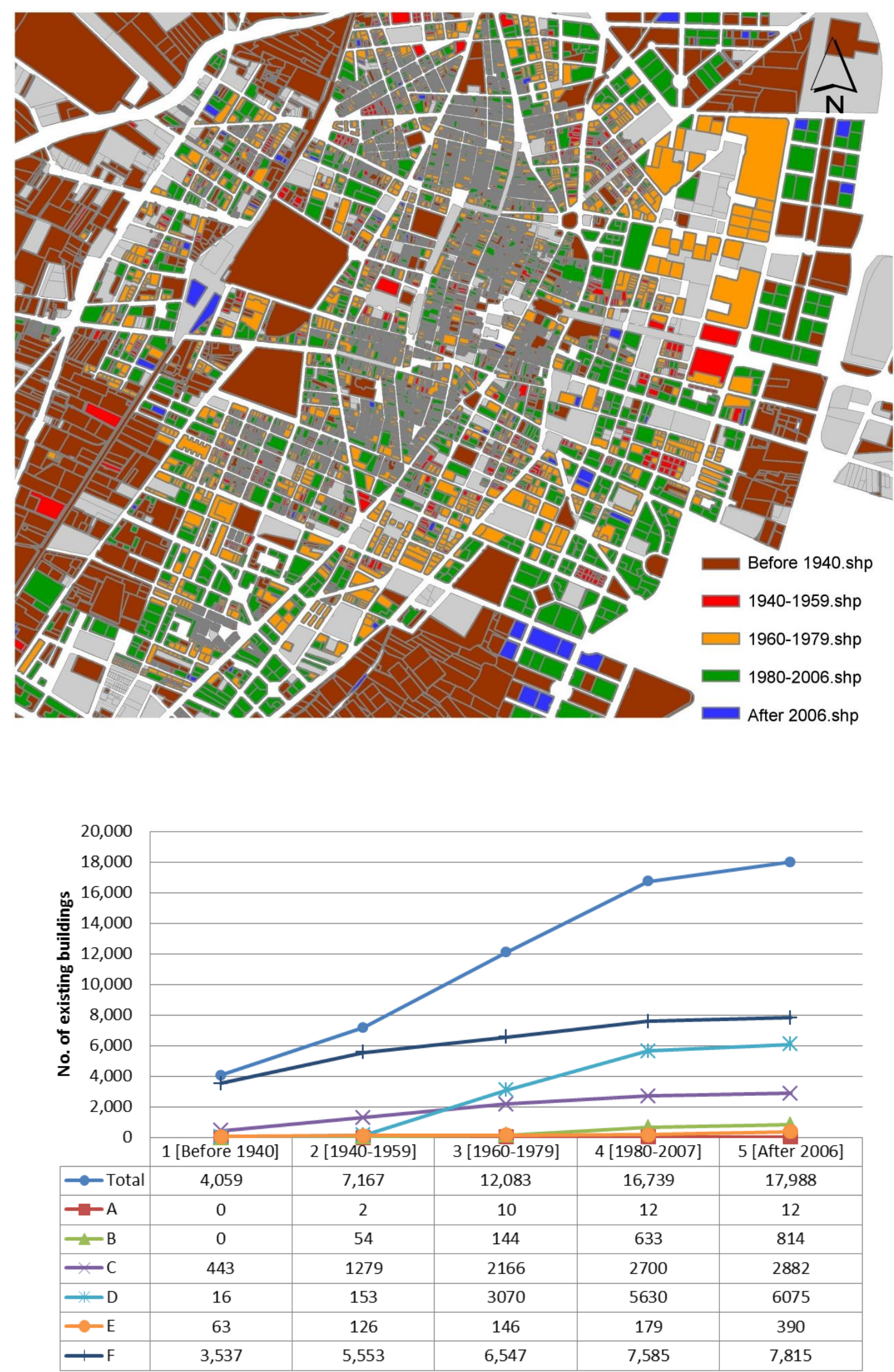


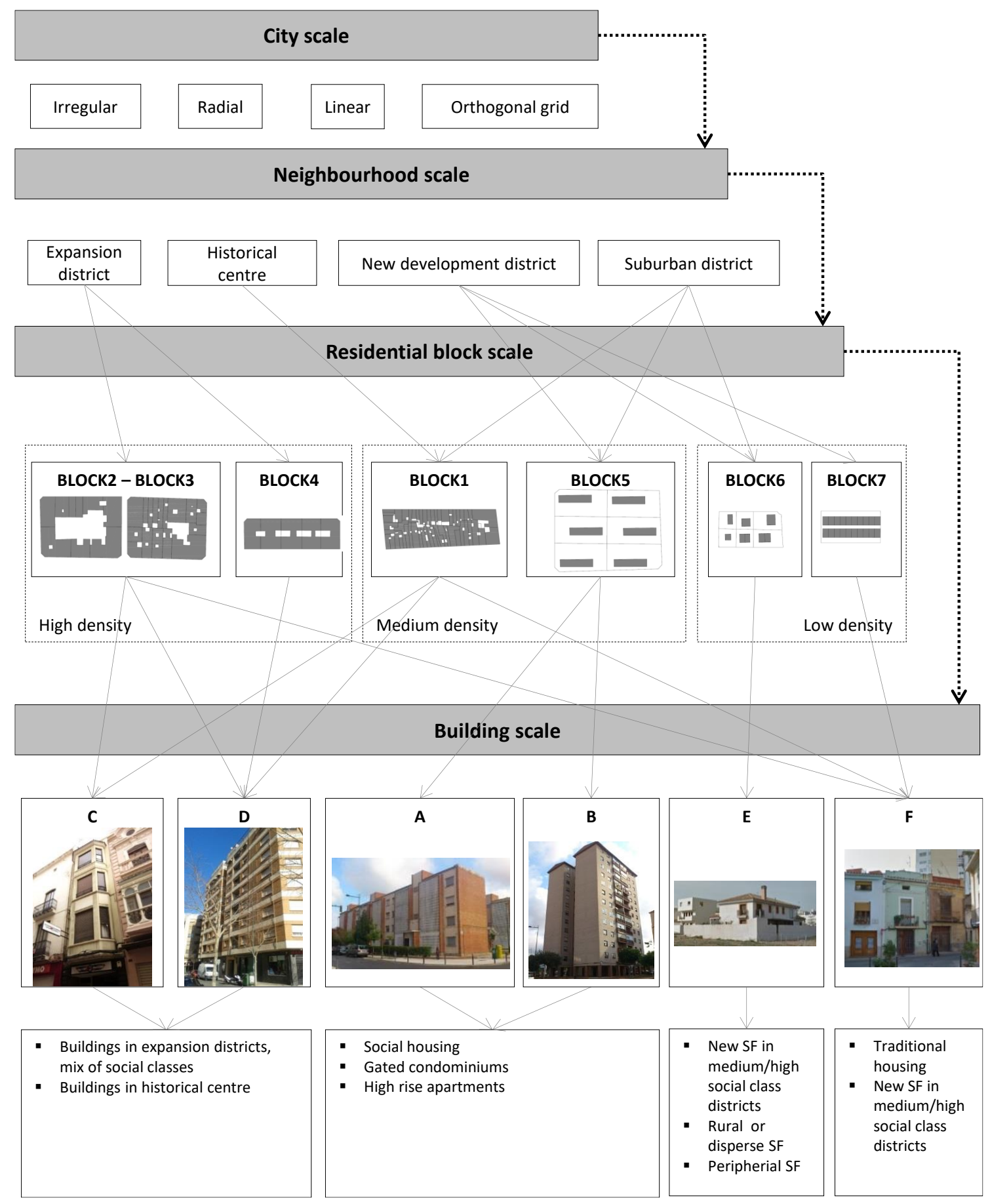




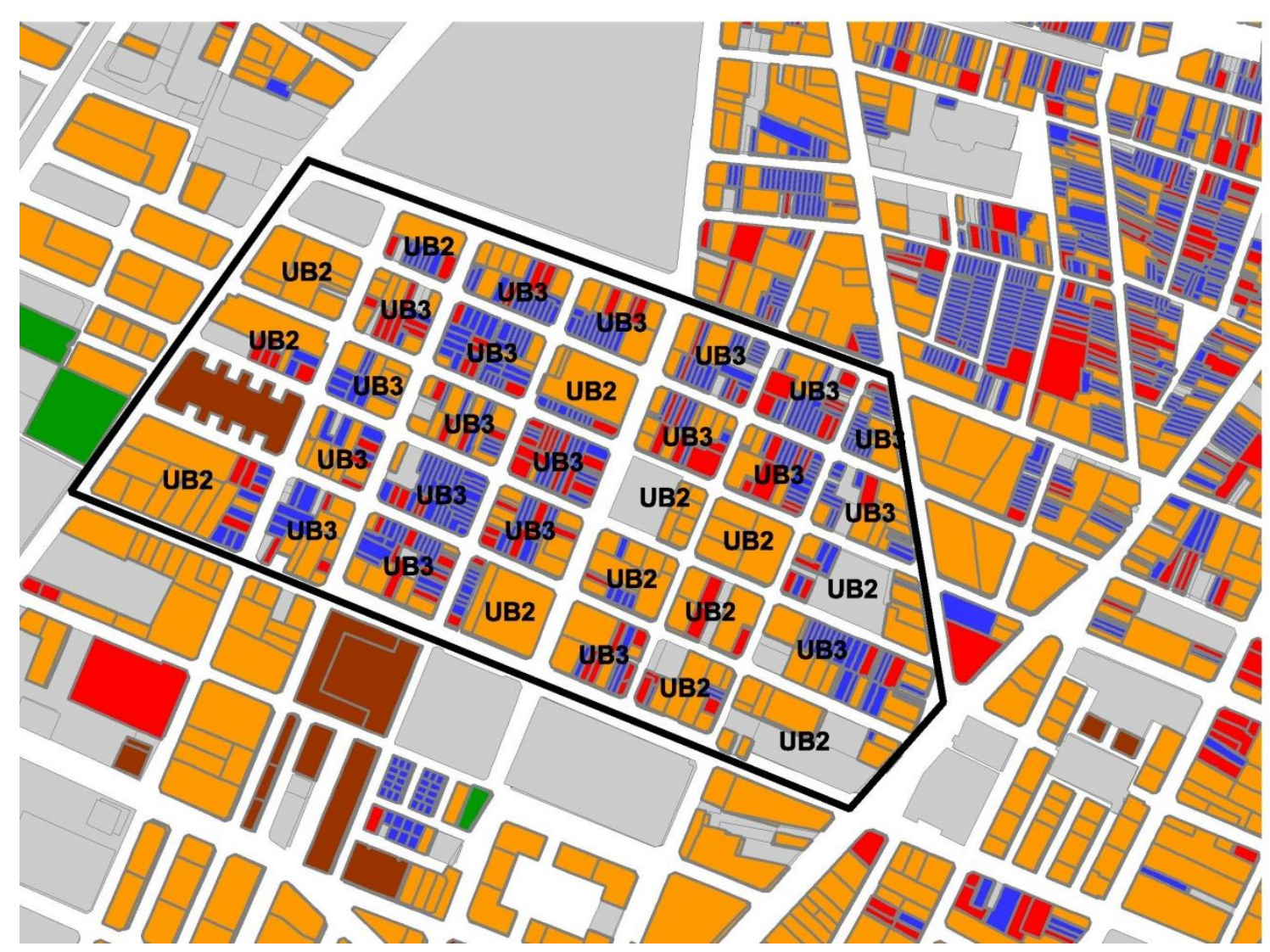

URBAN BLOCK 2

URBAN BLOCK 3
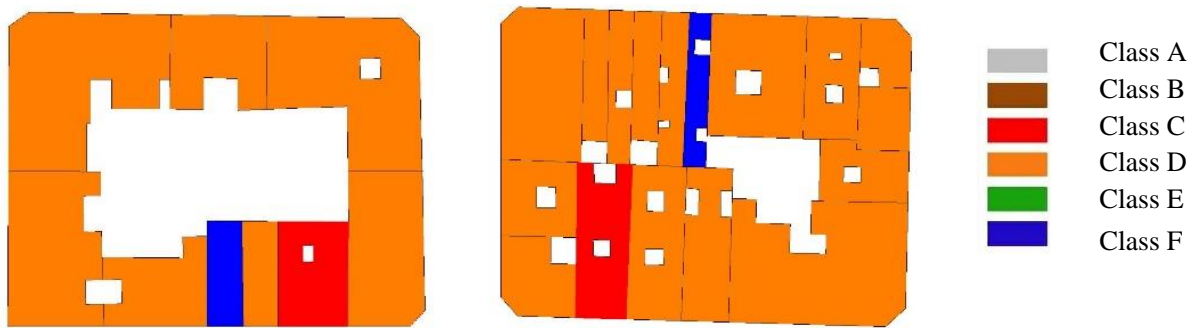

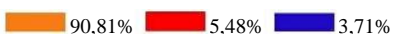

\begin{tabular}{l}
$63,78 \% \square$ \\
$\square-17,12 \%$ \\
\hline
\end{tabular} 